\title{
The Role of Sports Participation in the Association Between Students' Body Image Concerns and Disordered Eating
}

\author{
Vaiva Balčiūnienė, Rasa Jankauskienė, Miglẻ Bacevičienė \\ Lithuanian Sports University, Kaunas, Lithuania
}

\begin{abstract}
Background. Body image concerns (BICs) negatively influence young people's health as they mutilate psychosocial functioning and lifestyle. The present study aimed to compare BICs, socio-cultural attitudes towards appearance, and disordered eating (DE) in a large sample of student women and men of different body mass (BMI) and physical activity and to evaluate the mediating role of sports participation in the association between BICs and DE.

Methods. A total sample of 1850 students ( 1087 or $58.8 \%$ were women, average age $21.6 \pm 5.0$ years) participated in the study and completed a questionnaire measuring BICs, internalization of the socio-cultural appearance ideals, drive for muscularity, DE, physical activity (PA), and BMI. Two hundred eighty-two men and two hundred eightyeight women reported leisure-time participation in sports. Two-way ANOVA was conducted to test gender, BMI group, and sports participation effects on study variables. Moderated leisure-time exercise at a sports club effects were tested in the association between body image concerns (BICs) and disordered eating behaviours (DE).

Results. Overweight/obese students reported greater BICs, internalization of the stereotyped appearance ideals, and DE compared to students of normal body weight. Participants of sports clubs demonstrated higher appearance evaluation and body areas satisfaction; however, they reported higher overweight preoccupation, internalization of socio-cultural ideals, drive for muscularity (men), and DE. A higher level of BMI, BICs, internalization of sociocultural body ideals, and drive for muscularity (in men) were associated with greater DE in students. Participation in sports was not a significant moderator between BICs and DE. A significant interaction effect between BMI and exercising at a sports club was observed in women. Conditional effects demonstrated that female students with higher $\mathrm{BMI}$ and exercising at a sports club were at higher risk of $\mathrm{DE}(\beta=.18, p<.001)$ than women non-exercising at a sports club $(\beta=.13, p<.001)$.

Conclusions. Overweight students of both genders reported greater BICs and DE. Sports-involved students (men and women) demonstrated more favourable body appearance evaluation. However, sports participants of both genders demonstrated greater BICs and DE compared to non-exercisers. Sports participation had no significant mediating power on the associations between BICs and DE; however, women with higher BMI and participating in leisure-time sports faced a greater risk for DE than women with higher BMI but not participating in sports. The promotion of a positive body image was important to students, especially female students with higher BMI and participating in leisure sports.
\end{abstract}

Keywords: body image concerns, disordered eating, physical activity, sport clubs, emerging adults.

\section{INTRODUCTION}

$\mathrm{B}$ ody image concerns (BICs), body dissatisfaction (BD), disordered eating (DE), and eating disorders (EDs) are dominant health-related problems in youth that last from adolescence to adulthood (Karazsia, Murnen, \& Tylka, 2017; Neumark-Sztainer et al.,
2018; Potterton, Richards, Allen, \& Schmidt, 2020; Wang et al., 2019). BICs negatively influence young people's health as they mutilate psychosocial functioning and lifestyle. BICs, specifically BD, are related to lower self-esteem (Paxton, NeumarkSztainer, Hannan, \& Eisenberg, 2006) and self- 
compassion (Albertson, Neff, \& Dill-Shackleford, 2015), higher anxiety, and depression (Barnes, Abhyankar, Dimova, \& Best, 2020), suicidal ideation (Kim \& Kim, 2009), impairment in psychological and physical quality of life (da Silva, Campos, \& Marôco, 2018), sexual dysfunction (Seal, Bradford, \& Meston, 2009), DE (NeumarkSztainer, Paxton, Hannan, Haines, \& Story, 2006), and development of EDs (Rohde, Stice, \& Marti, 2015). Moreover, longitudinal studies have demonstrated that continuously increased BD from adolescence to young adulthood and engagement in DE during adolescence can predict the development of overweight/obesity in later years (Loth, Watts, Van Den Berg, \& Neumark-Sztainer, 2015; Yoon, Mason, Hooper, Eisenberg, \& Neumark-Sztainer, 2020).

The student population experiences an emerging adulthood period. Starting the self-support life on university/college campuses is considered a risky period, changing individuals' health-related attitudes and behaviours (Schwartz \& Petrova, 2019). A challenging university/college life, meeting high academic requirements, and adjustment into a new socio-cultural environment are identified as risk factors associated with the BD progression and may play a significant role in predicting DE severity (Howard, Romano, \& Heron, 2020). The symptoms of EDs tend to be worsening during the transition from school to university/college (Goldschen et al., 2019). Therefore, the exploration of BICs and DE in student samples is of great importance.

The prevalence of overweight and obesity in young people is increasing globally (Abarca-Gómez et al., 2017; Sa et al., 2019). Recent systematic reviews and meta-analyses have demonstrated that obese people report greater dissatisfaction with their bodies than the normal-weight ones (Weinberger, Kersting, Riedel-Heller, \& Luck-Sikorski, 2016). Studies have shown that overweight/obese students experience greater socio-cultural pressure on their body image, a higher level of $\mathrm{BD}$ and $\mathrm{DE}$, and the prevalence rates are higher among females than among males (El Ansari \& Berg-Beckhoff, 2019; Hricová, Orosová, Benka, Petkeviciene, \& Lukács, 2015; Lipson \& Sonneville, 2017; Moreno-Domínguez, Rutsztein, Geist, Pomichter, \& Cepeda-Benito, 2019; Nagata, Garber, Tabler, Murray, \& Bibbins-Domingo, 2018; Radwan et al., 2019). Despite the fact that BD reasons are universal, causes for greater BD in overweight/obese individuals can arise from intensified socio-cultural pressures (Weinberger et al., 2016). For instance, student women with higher body mass index (BMI) suffer from increased socio-cultural pressures and experience greater self-discrepancy, leading to the reinforced BD (Moreno-Domínguez et al., 2019). Next, weight and shape-based stigmatization, abusive weight-related comments, teasing, and bullying are more frequent among overweight/ obese emerging adults than their normal-weight counterparts (Herbozo, Menzel, \& Thompson, 2013; Waasdorp, Mehari, \& Bradshaw, 2018). As a consequence, for overweight/obese young people, the development of supportive social relationships (e.g., a lasting romantic relationship with a partner) can be faced with difficulties (Boyes \& Latner, 2009), and weight discrimination can pose a threat to health (Tomiyama et al., 2018). There is evidence that overweight/obese emerging adults more often engage in unhealthy weight control practices (e.g., dietary restraint, binge eating distinguished by loss of control, self-induced vomiting, laxative misuse, diet pills usage, excessive exercising) than their colleagues of normal BMI (Lipson \& Sonneville, 2017; Nagata et al., 2018; Radwan et al., 2019). The majority of studies have been implemented comparing BICs, socio-cultural attitudes towards appearance, and DE in women of different BMI; however, the present study aimed to provide more empirical data for student men.

Regular exercise and physical activity (PA) are recommended for young people because of their benefits to physical, mental, and social health (Breda et al., 2018; World Health Organization, 2018). Participation in PA and sport is related to a better body image in young people (Bassett-Gunter, McEwan, \& Kamarhie, 2017; Campbell \& Hausenblas, 2009; Sabiston, Pila, Vani, \& Thogersen-Ntoumani, 2019). More physically active students tend to have a more positive and functional body image (Soulliard, Kauffman, Fitterman-Harris, Perry, \& Ross, 2019). Nevertheless, research also shows that involvement in some sports (aesthetic, weight class, gravitational technical, and gravitational endurance) might be associated with the greater risk of developing BICs and DE (Bratland-Sanda \& Sundgot-Borgen, 2013; Sundgot-Borgen et al., 2013). The type of exercise (engaging in individual sports vs. team sports, weight-sensitive/not weight-sensitive sports) and exercise motivation are important variables mediating the associations between sports participation and DE (Chapman \& Woodman, 2015; Panão \& Carraça, 2020). Furthermore, some research showed that exercise within the sports club 
environment and police focused on the appearance or body weight change (e.g., pictures of ideal thin/ low body fat female or muscular men bodies, clothes emphasizing a slender body, mirrors for checking body forms) might foster self-objectification and $\mathrm{BD}$, which predicts BICs, drive for muscularity and DE in young women and men (Prichard \& Tiggemann, 2008; Prichard \& Tiggemann, 2012). It is important to understand the role of sports participation in the associations between body image (BI) and disordered eating (DE). There is a lack of these studies, especially on men.

The first aim of the present study was to compare BICs, socio-cultural attitudes towards appearance, and DE in a large sample of student women and men of different BMI. Based on the previous research, we predicted that overweight/obese students would report greater BICs, internalization of the sociocultural appearance ideals, and DE compared to normal body weight students. The second aim of the study was to compare BICs, internalization of the stereotyped beauty ideals, and DE in students of different patterns of leisure sports participation. We expected that sports clubs involved women and men would demonstrate a more favourable body image compared to non-sports club participants of both genders. The final aim of the study was to test the mediating role of sports participation in the associations between BICs and DE. We developed no assumptions for this aim.

\section{METHODS}

Research Procedure and Participants. We conducted a cross-sectional study in four major cities in Lithuania from April to October, 2019. The present study is part of a more extensive study recently published by the same authors (Baceviciene, Jankauskiene, \& Balciuniene, 2020a). However, the present study on the sample has a different research object and aims. Participants were recruited from Lithuanian state universities and colleges to participate in the survey. The researcher VB collected the data after receiving oral consent from the administrative staff in eleven universities and four colleges. The representativeness of the study sample was achieved by the conformity of the respondents to the numbers of students in four study areas. Thus, according to the distribution of the general numbers, the study sample included 763 men (41.2\%) and 1087 (58.8\%) women students who were enrolled in natural and agricultural (6.6\%), technology $(38.0 \%)$, medical and health $(27.5 \%)$, or social and humanities (27.3\%) study areas. Most of the sample $(83.0 \%$ of women and $96.9 \%$ of men) were students in the first cycle studies. The mean age of the sample was $21.6(\mathrm{SD}=5.0)$ years. For the data collection, an online questionnaire was used measuring BICs, socio-cultural influences on body image and appearance-related internalization, drive for muscularity (in men), DE, PA, and BMI. The procedure in completing the battery of the questionnaire was scheduled in-class time, with no time limit. In total, we received 1941 questionnaires, 56 individuals refused to participate in the survey (response rate was 97.1\%). The final study sample of 1850 participants provided all the information necessary for statistical analysis.

Ethical Statement. The study was handled under the principal of ethical and legal propositions of the research, and the protocol to conduct this study was approved by the Committee for Social Sciences Research Ethics of the Lithuanian Sports University (protocol No. SMTEK-7, 13-03-2019). The researchers described the purpose of the study to the students before the questionnaires were presented. Participants gave their consent for inclusion in the study while answering and marking the response, "I agree to participate" or "I disagree to participate." The survey has embraced the rules of anonymity, goodwill, and volunteering.

Measurements. Demographic Data. Demographic data were collected using demographic questions from the approved national survey of Health Behavior among Lithuanian Adult Population, 2014 (Grabauskas et al., 2015). The study participants indicated their gender, age, type of higher education institution (university or college), the level of study cycle, study area, study program, and year of study.

Body Mass Index. Self-reported height and weight data for the participants were received, and the Body Mass Index (BMI) value was calculated as body mass $(\mathrm{kg})$ divided by height squared $\left(\mathrm{m}^{2}\right)$. Students' BMI classification into body mass categories was conducted with the recommendation by the World Health Organization classification (World Health Organization, 1997). In accordance, BMI was categorized into four groups: underweight $\left(<18.5 \mathrm{~kg} / \mathrm{m}^{2}\right)$, normal weight (18.5-24.9 kg/m $\left.{ }^{2}\right)$, overweight $\left(25.0-29.9 \mathrm{~kg} / \mathrm{m}^{2}\right)$, and obese $\left(\geq 30.0 \mathrm{~kg} / \mathrm{m}^{2}\right)$. The results showed that BMI ranged from 14.0 to $47.3(\mathrm{M}=22.7, \mathrm{SD}=$ $3.7) \mathrm{kg} / \mathrm{m}^{2}$. The majority of the sample $(72.7 \%$ of 
women and $70.2 \%$ of men) was classified as normal body weight; $21.9 \%$ of men and $12.8 \%$ of women were overweight, and $3.9 \%$ and $4.2 \%$, respectively, obese. In further analyses, the overweight and obesity categories were combined. Even $10.3 \%$ ( $n=$ $112)$ of the women and $3.9 \%(n=30)$ of men who were underweight were excluded.

Body Image Concerns. The appearancerelated components of the body image construct were measured by the Multidimensional BodySelf Relations Questionnaire-Appearance Scales (MBSRQ-AS) (Brown, Cash, \& Mikulka, 1990). The 34-item instrument contains five subscales. The answer options are arranged on a 5-point Likert scale from 1 (definitely disagree or very dissatisfied) to 5 (definitely agree or very satisfied). MBSRQ-AS subscale scores were calculated as the means of the constituent items after reversing contraindicative, negatively worded items. The 7-item appearance evaluation subscale evaluates feelings of physical attractiveness or unattractiveness. Low scorers have general unhappiness with their physical appearance. The appearance orientation subscale consists of 12-items and shows the extent of investment in one's appearance. Low scorers less care about their appearance; their looks are not especially important, and they do not expend much effort to "look good". The body area satisfaction subscale of 9-items assesses satisfaction or dissatisfaction with particular areas of the body. Low scorers are unhappy about the size or appearance of several body areas. The 4-item overweight preoccupation subscale assesses a construct reflecting fat anxiety, weight vigilance, dieting, and eating restraint higher scores indicating a greater preoccupation with being overweight. The self-classified weight scale of 2-items explains how one perceives and identifies one's weight, from very underweight to very overweight. Higher scores show stronger beliefs that bodyweight is too high. The reliability and validity of the Lithuanian version of the MBSRQ-AS (LT-MBSRQ-AS) in a student population sample have been demonstrated (Miskinyte \& Bagdonas, 2010). The instrument was purchased from the author's (Thomas F. Cash, Ph.D.) official website. In the present sample, Cronbach's alphas for the LT-MBSRQ-AS were as follows: appearance evaluation, .83; appearance orientation, .79; body area satisfaction, .88; overweight preoccupation, .73; and self-classified weight, .85 .

Socio-Cultural Influences on Body Image and Appearance-Related Internalization. The level of socio-cultural influences on body image and appearance-related internalization was assessed by the Sociocultural Attitudes Towards Appearance Questionnaire-4 (SATAQ-4) (Schaefer et al., 2015). The 22-item self-report instrument comprises five subscales. Each subscale includes items with Likert-type answers from definitely disagree (1) to definitely agree (5). The higher score indicates a greater level of internalization or acceptance for the dominant socio-cultural standards of appearance. The 5-item thin/low body fat internalization subscale reports individuals' favour for the appearance of a thin and low-fat body. The athletic/muscular internalization subscale consists of 5-items and evaluates individuals' supposition that they should look athletic and muscular. The family pressure subscale of 4-items indicates family members' pressure to adhere to prevailing socio-cultural standards of appearance. The 4-item peer pressure subscale measures the extent to which individuals feel pressure from their peers to match social expectations of appearance. The media pressure subscale consists of 4 items and assesses how much respondents handle pressure from the media to conform to socially valued ideals of body appearance. The Lithuanian version of the SATAQ-4 (LT-SATAQ-4) has presented good psychometric properties in a student population sample (Baceviciene, Jankauskiene, \& Balciuniene, 2020b). In the present study, the internal consistency of the subscales of thin/low body fat internalization, athletic/muscular internalization, family pressure, peer pressure, and media pressure were $.91, .88$, $.90, .93$, and .98 , respectively. The Cronbach's alpha for the LT-SATAQ-4 global scale was .91.

Drivefor Muscularity. The Drive for Muscularity Scale (DMS) was used to evaluate attitudes and behaviours indicating the degree of preoccupation with body muscularity (McCreary, Sasse, Saucier, \& Dorsch, 2004). The self-report measure scale consists of 15 items rated on a 6-point Likert scale ranging from 1 (always) to 6 (never), and all items are reverse-coded before analyses. Higher scores indicate greater muscle development behaviours and a higher drive for muscularity. The instrument consists of two subscales. The 7-item muscularityoriented body image attitudes subscale reflects one's attitude toward the desire to rejig the current body shape and gain muscle mass. Also, the 7-item muscle development behaviours subscale shows the extent to which one engages in practices that promote a gain in muscle mass. It was determined 
that DMS could be a factor decomposed into two factors for men, but not for women (McCreary, 2007). For the present study, the general score of the scale was calculated in men. Good psychometric properties of the Lithuanian version of DMS (LT-DMS) in men student population sample has been confirmed (Bacevičienè, Titenyte, Balčiūnienè, \& Jankauskienè, 2020). In this study, Cronbach's alpha for the LT-DMS was .92 .

Disordered Eating. The 28-item self-report Eating Disorder Examination Questionnaire 6.0 (EDE-Q 6.0) was used to access disordered eating (Fairburn \& Beglin, 2008). The EDE-Q 6.0 evaluates the individual eating-related behaviours in the last 28 days and exhaustively measures the fundamental behavioural characteristics of disordered eating behaviour and/or eating disorders. In terms of the number of episodes of the behaviour or number of days on which the act happened, the six open-ended questions provide the frequency data of the fundamental behavioural characteristics of eating disorders, i.e., objective binge eating, self-induced vomiting, laxative use, and excessive exercise. Besides, 22 attitudinal questions of this instrument result in four subscales and indicate the severity of the disordered eating. The responses to the questions are carried out on a 7-point Likert scale ranging from 0 (no days) to 6 (every day). Higher scores determine either greater severity or frequency of disordered eating. Research supports the reliability and validity of the Lithuanian version of EDE-Q 6.0 (LT-EDE-Q 6.0) in the students' population sample (Baceviciene, Balciuniene, \& Jankauskiene, 2020). In the present study, internal consistency for LT-EDE-Q 6.0 global scale was good, namely .94 .

Leisure exercising at a sports club. Leisure exercising at a sports club (LESC) was assessed by a single question asking to evaluate students' participation in sports club exercising activities: "Do you exercise at a sports club/centre during your leisure time?". The possible answers were: "Yes, I do" or "No, I don't". This question was selfdeveloped for this study.

Statistical analysis. First, descriptive statistics of the sample was performed. The results are presented as the means and standard deviations and percentages according to the type of variable. The internal consistency of the study scales was examined using Cronbach's alpha. Next, two-way ANOVA was conducted to test gender, BMI group and leisure exercising at sports club effects on study variables. In addition, interaction effects between gender*BMI group and gender*exercising at sports club were tested with the partial eta squared $\left(\eta^{2}\right)$ to represent the effect sizes. The statistical analyses were carried out using IBM SPSS Statistics 26 (IBM Corp., Armonk, NY, USA). Finally, moderated leisure-time exercise at a sports club effects were tested in the association between body image concerns and disordered eating behaviours. Moderated mediation analysis was performed by using the PROCESS function V.3.5 in SPSS V.26 by A. F. Hayes (Rockwood \& Hayes, 2020). The model 1 (model as a parameter in the PROCESS function) was used for moderated analysis to test moderated effects of exercise at a sports club on all paths between BMI and body image concerns on disordered eating behaviours.

\section{RESULTS}

The comparison of the BICs, internalization of stereotyped beauty standards, DE, and drive for muscularity means for women and men students are presented in Table 1. The analysis of the results showed that BICs were greater for women. Compared to men, women scored significantly higher on appearance orientation, overweight preoccupation, and self-classified weight. Men were more satisfied with their body areas compared to women. Internalization of stereotyped body ideals was significantly greater in women compared to men.

Scores for perceived pressure, internalization of beauty standards, preoccupation with being overweight, self-classified weight, and DE were higher among men and women in the overweight/ obese group than those in the normal-weight group. It is also apparent that men and women with normal body weight had higher scores than those of the overweight/obese participants on appearance evaluation and body area satisfaction. As the variations were too small, LT-DMS scores are not presented for the female sample. We observed significant gender $\mathrm{x}$ BMI interactions for appearance evaluation, body area satisfaction, and disordered eating, suggesting that body image concerns and disordered eating are greater in women with overweight and obesity than in men.

Comparisons of the study variables means in men and women with different sports participation are displayed in Table 2. In women, exercising in sports clubs was associated with a significantly greater positive evaluation of body image (appearance 
Table 1. Comparison of body image concerns and disordered eating (mean; $95 \% C I)$ across gender and body mass index groups $(\boldsymbol{n}=\mathbf{1 8 5 0})$

\begin{tabular}{|c|c|c|c|c|c|c|c|c|c|c|c|c|c|c|c|c|c|}
\hline \multirow{4}{*}{ Characteristics } & \multicolumn{4}{|c|}{$\operatorname{Men}(n=733)$} & \multicolumn{4}{|c|}{ Women $(n=975)$} & \multirow{2}{*}{\multicolumn{3}{|c|}{ Gender }} & \multirow{2}{*}{\multicolumn{3}{|c|}{ BMI group }} & \multirow{2}{*}{\multicolumn{3}{|c|}{$\begin{array}{c}\text { Gender*BMI } \\
\text { group }\end{array}$}} \\
\hline & \multirow{2}{*}{\multicolumn{2}{|c|}{$\begin{array}{c}\text { Normal } \\
\text { weight } \\
n=536\end{array}$}} & \multirow{2}{*}{\multicolumn{2}{|c|}{$\begin{array}{c}\text { Overweight, } \\
\text { obesity } \\
n=197\end{array}$}} & \multirow{2}{*}{\multicolumn{2}{|c|}{$\begin{array}{c}\text { Normal } \\
\text { weight } \\
n=790\end{array}$}} & \multirow{2}{*}{\multicolumn{2}{|c|}{$\begin{array}{c}\text { Overweight, } \\
\text { obesity } \\
n=185\end{array}$}} & & & & & & & & & \\
\hline & & & & & & & & & \multirow{2}{*}{$F$} & \multirow{2}{*}{$\eta^{2}$} & \multirow{2}{*}{$p$} & \multirow{2}{*}{$F$} & \multirow{2}{*}{$\eta^{2}$} & \multirow{2}{*}{$p$} & \multirow{2}{*}{$F$} & \multirow{2}{*}{$\eta^{2}$} & \multirow{2}{*}{$p$} \\
\hline & M & $95 \%$ CI & $\mathbf{M}$ & $95 \%$ CI & $\mathbf{M}$ & $95 \%$ CI & $\mathbf{M}$ & $95 \%$ CI & & & & & & & & & \\
\hline Body Mass Index & 22.1 & $21.9-22.3$ & 28.0 & $27.7-28.3$ & 21.3 & $21.2-21.5$ & 28.4 & $28.1-28.7$ & 2.4 & .001 & .13 & 2685.9 & .61 & $<.001$ & 22.1 & .01 & $<.001$ \\
\hline \multicolumn{18}{|l|}{ LT-MBSRQ-AS: } \\
\hline $\begin{array}{l}\text { Appearance } \\
\text { Evaluation }\end{array}$ & 3.3 & $3.3-3.4$ & 3.0 & $2.9-3.1$ & 3.3 & $3.3-3.4$ & 2.7 & $2.6-2.8$ & 16.8 & .01 & $<.001$ & 116.4 & .06 & $<.001$ & 15.5 & .009 & $<.001$ \\
\hline $\begin{array}{l}\text { Appearance } \\
\text { Orientation }\end{array}$ & 3.1 & $3.1-3.1$ & 3.1 & $3.0-3.2$ & 3.6 & $3.5-3.6$ & 3.6 & $3.5-3.6$ & 190.6 & .10 & $<.001$ & .04 & .00 & .83 & .004 & .00 & .95 \\
\hline $\begin{array}{l}\text { Body Area } \\
\text { Satisfaction }\end{array}$ & 3.4 & $3.4-3.5$ & 3.3 & $3.2-3.4$ & 3.3 & $3.3-3.4$ & 2.9 & $2.8-3.0$ & 29.7 & .02 & $<.001$ & 46.6 & .03 & $<.001$ & 7.9 & .005 & .005 \\
\hline $\begin{array}{l}\text { Overweight } \\
\text { Preoccupation }\end{array}$ & 1.7 & $1.7-1.8$ & 2.3 & $2.2-2.4$ & 2.3 & $2.3-2.4$ & 2.8 & $2.7-2.9$ & 128.4 & .07 & $<.001$ & 108.6 & .06 & $<.001$ & .35 & .00 & .56 \\
\hline $\begin{array}{l}\text { Self-Classified } \\
\text { Weight }\end{array}$ & 2.7 & $2.6-2.7$ & 3.7 & $3.6-3.8$ & 3.1 & $3.1-3.2$ & 4.1 & $4.1-4.2$ & 191.8 & .10 & $<.001$ & 1069.5 & .39 & $<.001$ & .44 & .00 & .51 \\
\hline LT-SATAQ-4 & 2.0 & $2.0-2.1$ & 2.3 & $2.2-2.4$ & 2.4 & $2.3-2.4$ & 2.7 & $2.6-2.8$ & 84.2 & .05 & $<.001$ & 55.4 & .03 & $<.001$ & 1.4 & .001 & .23 \\
\hline Disordered Eating & .6 & $.5-.7$ & 1.3 & $1.1-1.4$ & 1.4 & $1.3-1.4$ & 2.4 & $2.2-2.5$ & 237.6 & .12 & $<.001$ & 189.6 & .10 & $<.001$ & 8.9 & .005 & .003 \\
\hline $\begin{array}{l}\text { Drive for } \\
\text { Muscularity }\end{array}$ & 2.7 & $2.6-2.8$ & 2.6 & $2.4-2.8$ & - & - & - & - & - & - & - & 1.6 & .002 & .020 & - & - & - \\
\hline
\end{tabular}

Notes. $M$ - mean; $C I$ - confidence interval; $p$ - significance level; $F$ - Fisher's statistics; $\eta^{2}$ - estimate of effect size; LT-SATAQ-4 - Lithuanian version of the Sociocultural Attitudes Towards Appearance Questionnaire-4; LT-MBSRQ-AS - Lithuanian version of the Multidimensional BodySelf Relations Questionnaire - Appearance Scales.

evaluation, body areas satisfaction) compared to non-exercisers. However, sports involved women reported greater overweight preoccupation, general internalization of stereotyped beauty ideals, and disordered eating. We observed greater appearance evaluation and appearance orientation in exercising men. However, overweight preoccupation, internalization of stereotyped beauty standards, and drive for muscularity were also greater in exercising men than in non-exercisers. Notably, we observed no gender*exercising at sports club interaction effects suggesting that body image concerns and disordered eating behaviours differences in sport club exercisers and non-exercises were similar in men and women groups.

Further, we tested the moderating effect of leisure-time exercise in a sports club in the association between BICs and DE in men (Table $3)$. The analysis of the results suggested that all analysed variables were associated with the DE in the expected direction: greater BMI, facets of the negative BI, internalization of beauty standards, and drive for muscularity increased DE, while positive appearance evaluation and body area satisfaction had a protective effect on DE. Moreover, a model of body area satisfaction and exercising at a sports club revealed that exercisers had higher DE behaviours as compared to non-exercisers. A significant interaction effect between exercising and body area satisfaction demonstrated no protective effect of positive body areas evaluation. Conditional protective effect of positive body areas satisfaction was higher in non-exercisers group $(\beta=-.41, p<$ $.001)$ as compared to exercisers $(\beta=-.24, p<.001)$. No other significant interactions between sports participation, body image, and other variables predicted disordered eating in men.

In women, body image concerns, internalization of beauty standards, and BMI were associated with the greater DE (Table 4). We observed that leisure time exercising at a sports club significantly increased DE behaviours in women in models together with BMI, appearance evaluation, body area satisfaction, and self-classified weight. Also, there was a significant interaction effect between BMI and exercising at a sports club. Conditional effects demonstrated that female students with higher BMI and exercising at a sports club were at higher risk of $\mathrm{DE}(\beta=.18, p<.001)$ than women non-exercising at a sports $\operatorname{club}(\beta=.13, p<.001)$. 
Table 2. Comparison of body image concerns and disordered eating (mean; $95 \% C l$ ) across genders and exercising at a sports club groups $(n=1850)$

\begin{tabular}{|c|c|c|c|c|c|c|c|c|c|c|c|c|c|c|c|c|c|}
\hline \multirow{4}{*}{ Characteristics } & \multicolumn{4}{|c|}{ Men $(n=763)$} & \multicolumn{4}{|c|}{ Women $(n=1087)$} & \multirow{2}{*}{\multicolumn{3}{|c|}{ Gender }} & \multirow{2}{*}{\multicolumn{3}{|c|}{ LESC }} & \multirow{2}{*}{\multicolumn{3}{|c|}{ Gender*LESC }} \\
\hline & \multirow{2}{*}{\multicolumn{2}{|c|}{$\begin{array}{l}\text { Not exercising } \\
\text { at sport club } \\
n=481\end{array}$}} & \multirow{2}{*}{\multicolumn{2}{|c|}{$\begin{array}{c}\text { Exercising at } \\
\text { sport club } \\
n=282\end{array}$}} & \multirow{2}{*}{\multicolumn{2}{|c|}{$\begin{array}{c}\text { Not exercising } \\
\text { at sport club } \\
n=799\end{array}$}} & \multirow{2}{*}{\multicolumn{2}{|c|}{$\begin{array}{c}\text { Exercising at } \\
\text { sport club } \\
n=\mathbf{2 8 8}\end{array}$}} & & & & & & & & & \\
\hline & & & & & & & & & \multirow{2}{*}{$F$} & \multirow{2}{*}{$\eta^{2}$} & \multirow{2}{*}{$p$} & \multirow{2}{*}{$F$} & \multirow{2}{*}{$\eta^{2}$} & \multirow{2}{*}{$p$} & \multirow{2}{*}{$F$} & \multirow{2}{*}{$\eta^{2}$} & \multirow{2}{*}{$p$} \\
\hline & M & $95 \%$ CI & $\mathbf{M}$ & $95 \%$ CI & $\mathbf{M}$ & $95 \%$ CI & M & $95 \% \mathrm{CI}$ & & & & & & & & & \\
\hline Body Mass Index & 23.1 & $22.8-23.5$ & 24.0 & $23.5-24.4$ & 22.1 & $21.8-22.3$ & 22.3 & $21.8-22.7$ & 56.1 & .029 & $<.001$ & 7.6 & .004 & .006 & 3.1 & .002 & .08 \\
\hline \multicolumn{18}{|l|}{ LT-MBSRQ-AS: } \\
\hline $\begin{array}{l}\text { Appearance } \\
\text { Evaluation }\end{array}$ & 3.1 & $3.1-3.2$ & 3.4 & $3.3-3.5$ & 3.2 & $3.1-3.2$ & 3.3 & $3.2-3.4$ & .08 & .00 & .78 & 25.8 & .014 & $<.001$ & 2.4 & .001 & .12 \\
\hline $\begin{array}{l}\text { Appearance } \\
\text { Orientation }\end{array}$ & 3.0 & $3.0-3.1$ & 3.2 & $3.1-3.2$ & 3.5 & $3.5-3.6$ & 3.6 & $3.6-3.7$ & 267.8 & .13 & $<.001$ & 16.6 & .009 & $<.001$ & .05 & .00 & .82 \\
\hline $\begin{array}{l}\text { Body Area } \\
\text { Satisfaction }\end{array}$ & 3.4 & $3.3-3.4$ & 3.5 & $3.4-3.5$ & 3.2 & $3.2-3.3$ & 3.4 & $3.3-3.4$ & 9.3 & .005 & .002 & 6.8 & .004 & .009 & .17 & .00 & .68 \\
\hline $\begin{array}{l}\text { Overweight } \\
\text { Preoccupation }\end{array}$ & 1.8 & $1.7-1.8$ & 2.0 & $1.9-2.1$ & 2.3 & $2.2-2.3$ & 2.6 & $2.5-2.7$ & 134.1 & .07 & $<.001$ & 38.8 & .02 & $<.001$ & .00 & .00 & .99 \\
\hline $\begin{array}{l}\text { Self-Classified } \\
\text { Weight }\end{array}$ & 2.9 & $2.8-2.9$ & 3.0 & $2.9-3.0$ & 3.2 & $3.1-3.3$ & 3.2 & $3.1-3.3$ & 64.0 & .03 & $<.001$ & 2.8 & .002 & .095 & .99 & .001 & .32 \\
\hline LT-SATAQ-4 & 2.0 & $2.0-2.1$ & 2.2 & $2.1-2.3$ & 2.3 & $2.3-2.4$ & 2.5 & $2.5-2.6$ & 82.5 & .04 & $<.001$ & 28.6 & .02 & $<.001$ & 1.6 & .001 & .21 \\
\hline Disordered Eating & .8 & $.7-.8$ & .9 & $.7-1.0$ & 1.4 & $1.3-1.5$ & 1.6 & $1.5-1.8$ & 169.8 & .08 & .001 & 8.6 & .005 & .003 & .9 & .00 & .35 \\
\hline Drive for Muscularity & 2.4 & $2.3-2.5$ & 3.1 & $3.0-3.2$ & - & - & - & - & - & - & - & 69.9 & .08 & $<.001$ & - & - & - \\
\hline
\end{tabular}

Notes. $M$ - mean; $C I$ - confidence interval; $p$ - significance level; $F$ - Fisher's statistics; $\eta^{2}$ - estimate of effect size; LT-SATAQ-4 - Lithuanian version of the Sociocultural Attitudes Towards Appearance Questionnaire-4; LT-MBSRQ-AS - Lithuanian version of the Multidimensional BodySelf Relations Questionnaire - Appearance Scales; LESC - leisure exercising at a sports club.

Table 3. Testing moderating effect of leisure-time exercise at a sports club in the association between body image concerns and disordered eating behaviours in men $(n=763)$

\begin{tabular}{|c|c|c|c|c|c|c|c|c|c|}
\hline Characteristics & $B$ & $t$ & $p$ & $E_{0}$ & $E_{1}$ & $p_{0}$ & $p_{1}$ & $R$ & $R^{2}$ \\
\hline BMI & .09 & 9.52 & $<.001$ & & & & & \multirow{3}{*}{.37} & \multirow{3}{*}{.13} \\
\hline LESC & .04 & .75 & .45 & & & & & & \\
\hline BMI*LESC & -.01 & -.70 & .48 & & & & & & \\
\hline \multicolumn{10}{|l|}{ LT-MBSRQ-AS: } \\
\hline Appearance Evaluation & -.43 & -8.77 & $<.001$ & & & & & \multirow{3}{*}{.37} & \multirow{3}{*}{.14} \\
\hline LSEC & .22 & 3.72 & .002 & & & & & & \\
\hline Appearance Evaluation*LSEC & .02 & .24 & .81 & & & & & & \\
\hline Appearance Orientation & .34 & 5.43 & $<.001$ & & & & & \multirow{3}{*}{.24} & \multirow{3}{*}{.06} \\
\hline LSEC & .07 & 1.13 & .26 & & & & & & \\
\hline Appearance Orientation*LESC & -.02 & -.19 & .85 & & & & & & \\
\hline Body Area Satisfaction & -.41 & -9.12 & $<.001$ & \multirow{3}{*}{-.41} & \multirow{3}{*}{-.24} & \multirow{3}{*}{$<.001$} & \multirow{3}{*}{$<.001$} & \multirow{3}{*}{.35} & \multirow{3}{*}{.12} \\
\hline LESC & .14 & 2.31 & .021 & & & & & & \\
\hline Body Area Satisfaction*LESC & .17 & 2.28 & .022 & & & & & & \\
\hline Overweight Preoccupation & .60 & 13.9 & $<.001$ & & & & & \multirow{3}{*}{.54} & \multirow{3}{*}{.29} \\
\hline LESC & -.05 & -.95 & .34 & & & & & & \\
\hline Overweight Preoccupation*LESC & -.02 & -.32 & .75 & & & & & & \\
\hline Self-classified Weight & .41 & 9.44 & $<.001$ & & & & & \multirow{3}{*}{.37} & \multirow{3}{*}{.14} \\
\hline LESC & .07 & 1.23 & .22 & & & & & & \\
\hline Self-classified weight*LESC & -.04 & -.48 & .63 & & & & & & \\
\hline LT-SATAQ-4 & .56 & 11.95 & $<.001$ & & & & & \multirow{3}{*}{.49} & \multirow{3}{*}{.24} \\
\hline LESC & .02 & .30 & .77 & & & & & & \\
\hline LT-SATAQ-4*LESC & .10 & 1.22 & .22 & & & & & & \\
\hline LT-DMS & .16 & 4.44 & $<.001$ & & & & & \multirow{3}{*}{.21} & \multirow{3}{*}{.04} \\
\hline LESC & .01 & .16 & .87 & & & & & & \\
\hline LT-DMS*LESC & -.02 & -.37 & .71 & & & & & & \\
\hline
\end{tabular}

Notes. $B$ - nonstandardized regression coefficient; $t-t$ test for regression coefficient; $p$ - level of statistical significance; in a case of interaction $\mathrm{CE}_{0}, p_{0}$ - conditional effects and statistical significance for non exercises; $\mathrm{CE}_{1}, p_{1}-$ conditional effects and statistical significance for exercises; $R, R^{2}$ - model summary statistics; BMI - body mass index; LT-MBSRQ-AS - Lithuanian version of the Multidimensional Body-Self Relations Questionnaire - Appearance Scales; LT-SATAQ-4 - Lithuanian version of the Sociocultural Attitudes Towards Appearance Questionnaire-4; LT-DMS - Lithuanian version of the Drive for Muscularity Scale; LESC - leisure exercising at a sports club. 
Table 4. Testing moderating effect of leisure-time exercise at a sports club in the association between body image concerns and disordered eating behaviours in women $(n=1087)$

\begin{tabular}{|c|c|c|c|c|c|c|c|c|c|}
\hline Characteristics & $B$ & $t$ & $p$ & $E_{0}$ & $E_{1}$ & $p_{0}$ & $p_{1}$ & $R$ & $R^{2}$ \\
\hline BMI & .13 & 12.62 & $<.001$ & \multirow{3}{*}{.13} & \multirow{3}{*}{.18} & \multirow{3}{*}{$<.001$} & \multirow{3}{*}{$<.001$} & \multirow{3}{*}{.43} & \multirow{3}{*}{.19} \\
\hline LESC & .18 & 2.39 & .02 & & & & & & \\
\hline BMI*LESC & .04 & 2.00 & .046 & & & & & & \\
\hline \multicolumn{10}{|l|}{ LT-MBSRQ-AS: } \\
\hline Appearance Evaluation & -.91 & -22.32 & $<.001$ & & & & & \multirow{3}{*}{.62} & \multirow{3}{*}{.38} \\
\hline LESC & .35 & 5.11 & $<.001$ & & & & & & \\
\hline Appearance Evaluation*LESC & -.01 & -.12 & .90 & & & & & & \\
\hline Appearance Orientation & .64 & 8.65 & $<.001$ & & & & & \multirow{3}{*}{.31} & \multirow{3}{*}{.10} \\
\hline LESC & .14 & 1.67 & .09 & & & & & & \\
\hline Appearance Orientation*LESC & .08 & .56 & .57 & & & & & & \\
\hline Body Area Satisfaction & -.95 & -19.90 & $<.001$ & & & & & \multirow{3}{*}{.58} & \multirow{3}{*}{.34} \\
\hline LESC & .33 & 1.68 & $<.001$ & & & & & & \\
\hline Body Area Satisfaction*LESC & .02 & .17 & .87 & & & & & & \\
\hline Overweight Preoccupation & .95 & 28.33 & $<.001$ & & & & & \multirow{3}{*}{.71} & \multirow{3}{*}{.50} \\
\hline LESC & -.03 & -.50 & .61 & & & & & & \\
\hline Overweight Preoccupation*LESC & -.08 & -1.20 & .23 & & & & & & \\
\hline Self-classified Weight & .98 & 20.21 & $<.001$ & & & & & \multirow{3}{*}{.58} & \multirow{3}{*}{.34} \\
\hline LESC & .19 & 2.71 & .007 & & & & & & \\
\hline Self-classified weight*LESC & .13 & 1.28 & .20 & & & & & & \\
\hline LT-SATAQ-4 & 1.07 & 24.19 & $<.001$ & & & & & \multirow{3}{*}{.66} & \multirow{3}{*}{.43} \\
\hline LESC & -.05 & -.83 & .41 & & & & & & \\
\hline LT-SATAQ-4*LESC & .06 & .72 & .47 & & & & & & \\
\hline
\end{tabular}

Notes. $\mathrm{B}$ - nonstandardized regression coefficient; $\mathrm{t}-\mathrm{t}$ test for regression coefficient; $\mathrm{p}$ - level of statistical significance; $\mathrm{CE}_{0}$, $\mathrm{p}_{0}-\mathrm{conditional}$ effects and statistical significance for non exercises; $\mathrm{CE}_{1}, \mathrm{p}_{1}$ - conditional effects and statistical significance for exercises; $\mathrm{R}, \mathrm{R}^{2}-$ model summary statistics; BMI - body mass index; LT-MBSRQ-AS - Lithuanian version of the Multidimensional Body-Self Relations Questionnaire - Appearance Scales; LT-SATAQ-4 - Lithuanian version of the Sociocultural Attitudes Towards Appearance Questionnaire-4; LESC - leisure exercising at a sports club.

\section{DISCUSSION}

The first aim of the present study was to compare BICs, socio-cultural attitudes towards appearance, and DE in a large sample of student women and men of different BMI. Based on the previous research, we predicted that overweight/obese students would report greater BICs, internalization of the sociocultural appearance ideals, and DE compared to normal body weight students. This assumption was fully confirmed. The present study results showed that overweight/obese students of both genders reported significantly greater BICs, internalization of the stereotyped beauty ideals, and DE. Our study's findings resonate with studies in other countries where the apparent positive association between increased BMI and worsened BICs was observed in students (El Ansari \& Berg-Beckhoff, 2019; Richardson, Madzima, \& Nepocatych, 2019). Our study's findings showed that positive aspects of body image (appearance evaluation and satisfaction with body areas) were significantly weaker in overweight/obese students than those of normal body weight. The present study results overlap findings from other studies demonstrating that overweight/obese students experience greater socio-cultural pressure on their body image and a higher internalization of appearance ideals compared to students of normal body weight (Hasan et al., 2018; Moreno-Domínguez et al., 2019; Musaiger \& Al-Mannai, 2013). They also get more negative weight and shape-related comments than their normal-weight counterparts (Herbozo et al., 2013).

Finally, students in the overweight/obese group reported greater DE. These findings align with the conclusions of other studies in student samples, reporting a greater prevalence of DE in overweight/ obese students (Barrack, West, Christopher, \& Pham-Vera, 2019; Lipson \& Sonneville, 2017; Nagata et al., 2018). Notably, the present study adds to the knowledge that overweight men demonstrate the same BICs and dysfunctional eating tendencies as women do. It is essential to implement universal prevention programs for positive BI promotion and $\mathrm{DE}$ prevention for students of both genders and different BMI.

The second aim of the study was to compare BICs, internalization of the stereotyped beauty ideals, and DE in students of different patterns of 
leisure sports participation. We expected that sports clubs involved women and men will demonstrate a more favourable body image compared to sport-club non-participants in both genders. This assumption was also confirmed. Our study demonstrated that sports involved women experienced greater positive aspects of body image, e.g., appearance evaluation and body area satisfaction, compared to women who did not participate in sports. Those findings go in line with other studies (Campbell \& Hausenblas, 2009; Sabiston et al., 2019; Soulliard et al., 2019). However, the comparison of study variables between groups showed that women involved in exercising at sports clubs reported greater internalization of the beauty appearance ideals, overweight preoccupation, and DE. Explanations might be given based on several facts. Studies have demonstrated that sports participation has a favourable influence on BI only if it is intrinsically motivated (Panão \& Carraça, 2020). Therefore, women, who exercise for external goals, such as appearance improvement or social recognition, might feel lower internal autonomy and sports competence. Exercise within the sports club environment that focused on the appearance or body weight change might foster the development of DE (Prichard \& Tiggemann, 2008; Prichard \& Tiggemann, 2012). There is evidence that involvement in some sports (aesthetic, weight class, gravitational technical, and gravitational endurance) might be associated with the greater risk of BICs and DE development (BratlandSanda \& Sundgot-Borgen, 2013; Sundgot-Borgen et al., 2013). The type of exercise (engaging in individual sports vs. team sports, weight-sensitive/ not weight-sensitive sports) and exercise motivation are important variables mediating the associations between sports participation and DE (Chapman \& Woodman, 2015; Panão \& Carraça, 2020). However, these variables were not assessed in the present study, and that might be considered as the limitations of the present study. Future studies are recommended to address this issue.

The final aim of the study was to test the mediating role of sports participation in the associations between BICs and DE. The findings of the present study suggested that all analysed variables were associated with the $\mathrm{DE}$ in the expected direction: greater BMI, facets of the negative BI, internalization of beauty standards, and drive for muscularity (in men) increased $\mathrm{DE}$, while positive appearance evaluation and body area satisfaction had a protective effect on
DE. No significant interactions between sports participation, body image, and other variables predicted disordered eating in men suggesting that sport has no mediating role between BICs and DE in male students. No protective effect of greater satisfaction with body areas was observed in interactions between men's sports participation, BICs, and DE, suggesting that it is important to implement general strategies to decrease BIC's in sport participating men preventing DE in sport. However, in the present study, we did not assess positive body image, i.e., body appreciation that might be a stronger mediator between BICs and $\mathrm{DE}$ in exercising men (Jankauskiene, Baceviciene, \& Trinkuniene, 2020; Tylka \& Wood-Barcalow, 2015). Future studies should test this issue.

However, for women, we observed that leisure sports participation significantly increased $\mathrm{DE}$ together with BICs and internalization of the stereotyped beauty ideals (Table 4). These findings align with other studies demonstrating that participation in sports is the risk factor for the DE in women (Lechner, Gill, Drees, Hamady, \& Ludy, 2019; Prichard \& Tiggemann, 2008; Prichard \& Tiggemann, 2012). We observed no significant interactions between sports participation and BICs predicting DE in female students suggesting that sports participation per se is not a mediator between BICs and DE. However, we observed a significant interaction effect between BMI and exercising at a sports club in women. Our results demonstrated that female students with higher BMI and exercising at a sports club were at a higher risk of DE than women non-exercising at a sports club. Thus, the findings of the present study suggest that it is important to create and implement selected prevention programs fostering positive body image and decreasing BICs in leisure sport and exercise involved women with higher BMI. The body image concerns prevention-related education of coaches working with female students of different BMI in various sports, and physical activity types are also of great importance.

Summing up, leisure sports participation does not moderate the association between BICs and DE in female and male students. In other words, if a student is BI concerned, leisure sports participation does not change the probability of the development of DE. The exception is the female students with a higher BMI and participating in leisure sports. The explanation might be the contradiction between the higher BMI and the athletic demands in sports. 
This contradiction might be especially strong in sports where lower body weight is an advantage or in recreational fitness activities with a strong focus on appearance improvement (Sundgot-Borgen et al., 2013). However, we did not evaluate the type and nature of participation in leisure-time sports that might be considered the limitation of the study.

The present study has important limitations worth discussing. The cross-sectional design of the study prevents drawing conclusions about the causality of associations. Sports participation might increase BICs, especially if appearance improvement-oriented or lower body weight is advantageous for the sports results. However, it might be that students with a higher BMI and overweight preoccupation are more engaged in leisure-time sport and fitness activities with the aim to decrease body weight. The design of the present study prevents from answering those questions. Thus, future studies might benefit from experimental or longitudinal designs. Further, the nature, type of sports participation, and motivation of the exercise should be assessed in future studies. Finally, studying positive, but not only negative body image should be encouraged in future studies since positive body image includes not only the evaluation of the appearance but also possesses a much broader conception, including respect to the body and body appreciation that helps to prevent DE (Tylka \& Wood-Barcalow, 2015).

Our study has several strengths that should be taken into consideration. The important strength is a large study sample of both genders representing various study areas of Lithuanian universities and colleges. A large sample size assured us to conduct analyses with sufficient statistical power. Next, our study employed valid and reliable instruments widely used by researchers, such as the EDE-Q 6.0, SATAQ-4, MBSRQ-AS, and DMS. Finally, the present study adds empirical knowledge that sportsinvolved students demonstrate more favourable body image, yet they show more BICs and DE. Sports participation has no significant power on the associations between BICs and DE; however, women with higher BMI and participating in leisure-time sports face a greater risk for DE than women with higher BMI but not participating in sports. These results have important implications for practice.

\section{CONCLUSIONS}

Overweight students of both genders reported greater $\mathrm{BICs}$ and DE. Sports-involved students (men and women) demonstrated more favourable body appearance evaluation. However, sports participants of both genders demonstrated greater BICs and DE compared to non-exercisers. Sports participation had no significant mediating effect on the associations between BICs and DE; however, women with higher BMI and participating in leisure-time sports faced a greater risk for DE than women with higher BMI but not participating in sports. The promotion of a positive body image is important for students (men and women), especially for female students with higher BMI and participating in leisure sports.

Author Contributions: RJ and $\mathrm{MB}$ were involved in conceptualization; RJ, MB and VB were involved in methodology, validation, investigation, resources, writing - original draft preparation and writing - review and editing; $\mathrm{MB}$ and $\mathrm{VB}$ were involved in software, formal analysis and data curation; RJ was involved in supervision and project administration. All authors have read and agreed to the published version of the manuscript.

Funding: This research received no external funding.

\section{REFERENCES}

Abarca-Gómez, L., Abdeen, Z. A., Hamid, Z. A., AbuRmeileh, N. M., Acosta-Cazares, B., Acuin, C., ... Ezzati, M. (2017). Worldwide trends in body-mass index, underweight, overweight, and obesity from 1975 to 2016: A pooled analysis of 2416 populationbased measurement studies in 128. 9 million children, adolescents, and adults. The Lancet, 390(10113), 26272642. doi: 10.1016/S0140-6736(17)32129-3

Albertson, E. R., Neff, K. D., \& Dill-Shackleford, K. E. (2015). Self-compassion and body dissatisfaction in women: A randomized controlled trial of a brief meditation intervention. Mindfulness, 6(3), 444-454. doi: 10.1007/s12671-014-0277-3

Baceviciene, M., Balciuniene, V., \& Jankauskiene, R. (2020). Validation of the Lithuanian version of the eating disorder examination questionnaire 6.0 in a student sample. Brain and Behavior, 10(3), e01555. doi: 10.1002/brb3.1555

Baceviciene, M., Jankauskiene, R., \& Balciuniene, V. (2020a). The role of body image, disordered eating and lifestyle on the quality of life in Lithuanian university students. International Journal of Environmental 
Research and Public Health, 17(5), 1593. doi: 10.3390/ ijerph17051593

Baceviciene, M., Jankauskiene, R., \& Balciuniene, V. (2020b). Validation of the Lithuanian version of the sociocultural attitudes towards appearance questionnaire-4 (SATAQ-4) in a student sample. International Journal of Environmental Research and Public Health, 17(3), 932. doi: 10.3390/ijerph17030932 Bacevičienè, M., Titenytè, Ž, Balčiūnienè, V., \& Jankauskienè, R. (2020). Drive for muscularity in Lithuanian male students: Psychometrics and associated characteristics. Baltic Journal of Sport and Health Sciences, 1(116), 20-27. doi: 10.33607/bjshs.v1i116.899 Barnes, M., Abhyankar, P., Dimova, E., \& Best, C. (2020). Associations between body dissatisfaction and self-reported anxiety and depression in otherwise healthy men: A systematic review and meta-analysis. PLoS ONE, 15(2), e0229268. doi: 10.1371/journal.pone.0229268

Barrack, M. T., West, J., Christopher, M., \& PhamVera, A. (2019). Disordered eating among a diverse sample of first-year college students. Journal of the American College of Nutrition, 38(2), 141-148. doi: 10.1080/07315724.2018.1487345

Bassett-Gunter, R., McEwan, D., \& Kamarhie, A. (2017). Physical activity and body image among men and boys: A meta-analysis. Body Image, 22, 114-128. doi: 10.1016/j.bodyim.2017.06.007

Boyes, A. D., \& Latner, J. D. (2009). Weight stigma in existing romantic relationships. Journal of Sex and Marital Therapy, 35(4), 282-293. doi: 10.1080/00926230902851280

Bratland-Sanda, S., \& Sundgot-Borgen, J. (2013). Eating disorders in athletes: Overview of prevalence, risk factors and recommendations for prevention and treatment. European Journal of Sport Science, 13(5), 499-508. doi: 10.1080/17461391.2012.740504

Breda, J., Jakovljevic, J., Rathmes, G., Mendes, R., Fontaine, O., Hollmann, S., ... Galea, G. (2018). Promoting health-enhancing physical activity in europe: Current state of surveillance, policy development and implementation. Health Policy, 122(5), 519-527. doi: 10.1016/j.healthpol.2018.01.015

Brown, T. A., Cash, T. F., \& Mikulka, P. J. (1990). Attitudinal body-image assessment: Factor analysis of the body-self relations questionnaire. Journal of Personality Assessment, 55(1-2), 135-144. doi: 10.1080/00223891.1990.9674053

Campbell, A., \& Hausenblas, H. A. (2009). Effects of exercise interventions on body image: A metaanalysis. Journal of Health Psychology, 14(6), 780-793. doi:10.1177/1359105309338977

Chapman, J., \& Woodman, T. (2015). Disordered eating in male athletes: Ameta-analysis. Journal of Sports Sciences, 34(2), 101-109. doi: 10.1080/02640414.2015.1040824

da Silva, W. R., Campos, J. A. D. B., \& Marôco, J. (2018). Impact of inherent aspects of body image, eating behavior and perceived health competence on quality of life of university students. PloS ONE, 13(6), e0199480. doi: 10.1371/journal.pone.0199480
El Ansari, W., \& Berg-Beckhoff, G. (2019). Association of health status and health behaviors with weight satisfaction vs. body image concern: Analysis of 5888 undergraduates in Egypt, Palestine, and Finland. Nutrients, 11(12), 2860. doi: 10.3390/nu11122860

Fairburn, C. G., \& Beglin, S. J. (2008). Eating disorder examination questionnaire (EDE-Q 6.0). In C. G. Fairburn (Ed.), Cognitive behavior therapy and eating disorders (pp. 309-313). New York, USA: The Guilford Press.

Godin, G., \& Shephard, R. J. (1985). A simple method to assess exercise behavior in the community. Canadian Journal of Applied Sport Sciences, 10(3), 141-146.

Goldschen, L., Lundblad, W., Fertig, A. M., Auster, L. S., Schwarzbach, H. L., \& Chang, J. C. (2019). Navigating the university transition among women who self-report an eating disorder: A qualitative study. International Journal of Eating Disorders, 52(7), 795-800. doi: 10.1002/eat.23071

Grabauskas, V. J., Klumbiene, J., Petkevicienė, J., Sakyte, E., Kriaucioniene, V., \& Veryga, A. (2015). Health behaviour among Lithuanian adult population, 2014. Kaunas, Lithuania: Lithuanian University of Health Sciences.

Hasan, H. A., Najm, L., Zaurub, S., Jami, F., Javadi, F., Deeb, L. A., ... Radwan, H. (2018). Eating disorders and body image concerns as influenced by family and media among university students in Sharjah, UAE. Asia Pacific Journal of Clinical Nutrition, 27(3), 695-700. doi: 10.6133/apjen.062017.10

Herbozo, S., Menzel, J. E., \& Thompson, J. K. (2013). Differences in appearance-related commentary, body dissatisfaction, and eating disturbance among college women of varying weight groups. Eating Behaviors, 14(2), 204-206. doi: 10.1016/j.eatbeh.2013.01.013

Howard, L. M., Romano, K. A., \& Heron, K. E. (2020). Prospective changes in disordered eating and body dissatisfaction across women's first year of college: The relative contributions of sociocultural and college adjustment risk factors. Eating Behaviors, 36, 101357. doi: 10.1016/j.eatbeh.2019.101357

Hricová, L., Orosová, O., Benka, J., Petkeviciene, J., \& Lukács, A. (2015). Body dissatisfaction, body mass index and self-determination among university students from Hungary, Lithuania and Slovakia. Ceska a Slovenska Psychiatrie, 111(2), 64-71.

Jankauskiene, R., Baceviciene, M., \& Trinkuniene, L. (2020). Examining body appreciation and disordered eating in adolescents of different sports practice: Crosssectional study. International Journal of Environmental Research and Public Health, 17(11), 4044. doi: 10.3390/ ijerph17114044

Karazsia, B. T., Murnen, S. K., \& Tylka, T. L. (2017). Is body dissatisfaction changing across time? A crosstemporal meta-analysis. Psychological Bulletin, 143(3), 293-320. doi: 10.1037/bul0000081

Kim, D., \& Kim, H. (2009). Body-image dissatisfaction as a predictor of suicidal ideation among Korean boys 
and girls in different stages of adolescence: A two-year longitudinal study. Journal of Adolescent Health, 45(1), 47-54. doi: 10.1016/j.jadohealth.2008.11.017

Lechner, T. E., Gill, E. M., Drees, M. J., Hamady, C. M., \& Ludy, M. (2019). Prevalence of disordered eating and muscle dysmorphia in college students by predominant exercise type. International Journal of Exercise Science, 12(4), 989-1000.

Lipson, S. K., \& Sonneville, K. R. (2017). Eating disorder symptoms among undergraduate and graduate students at 12 US colleges and universities. Eating Behaviors, 24, 81-88. doi: 10.1016/j.eatbeh.2016.12.003

Loth, K. A., Watts, A. W., Van Den Berg, P., \& NeumarkSztainer, D. (2015). Does body satisfaction help or harm overweight teens? A 10-year longitudinal study of the relationship between body satisfaction and body mass index. Journal of Adolescent Health, 57(5), 559-561. doi: 10.1016/j.jadohealth.2015.07.008

McCreary, D. R., Sasse, D. K., Saucier, D. M., \& Dorsch, K. D. (2004). Measuring the drive for muscularity: Factorial validity of the drive for muscularity scale in men and women. Psychology of Men and Masculinities, 5(1), 49-58. doi: 10.1037/1524-9220.5.1.49

McCreary, D. R. (2007). The drive for muscularity scale: Description, psychometrics, and research findings. In J. K. Thompson, \& G. Cafri (Eds.), The muscular ideal: Psychological, social, and medical perspectives (1st. ed., pp. 87-106). Washington, USA: American Psychological Association.

Miskinyte, A., \& Bagdonas, A. (2010). Body image relationship with demographic variables in young adults. Psichologija, 42, 85-101.

Moreno-Domínguez, S., Rutsztein, G., Geist, T. A., Pomichter, E. E., \& Cepeda-Benito, A. (2019). Body mass index and nationality (Argentine vs Spanish) moderate the relationship between internalization of the thin ideal and body dissatisfaction: A conditional mediation model. Frontiers in Psychology, 10, 582. doi: 10.3389/fpsyg.2019.00582

Musaiger, A. O., \& Al-Mannai, M. (2013). Role of obesity and media in body weight concern among female university students in Kuwait. Eating Behaviors, 14(2), 229-232. doi: 10.1016/j.eatbeh.2012.12.004

Nagata, J. M., Garber, A. K., Tabler, J. L., Murray, S. B., \& Bibbins-Domingo, K. (2018). Prevalence and correlates of disordered eating behaviors among young adults with overweight or obesity. Journal of General Internal Medicine, 33(8), 1337-1343. doi: 10.1007/s11606-0184465-z

Neumark-Sztainer, D., Paxton, S. J., Hannan, P. J., Haines, J., \& Story, M. (2006). Does body satisfaction matter? Five-year longitudinal associations between body satisfaction and health behaviors in adolescent females and males. Journal of Adolescent Health, 39(2), 244-251. doi: 10.1016/j.jadohealth.2005.12.001

Neumark-Sztainer, D., Wall, M. M., Chen, C., Larson, N. I., Christoph, M. J., \& Sherwood, N. E. (2018). Eating, activity, and weight-related problems from adolescence to adulthood. American Journal of Preventive Medicine, 55(2), 133-141. doi: 10.1016/j. amepre.2018.04.032

Panão, I., \& Carraça, E. V. (2020). Effects of exercise motivations on body image and eating habits/behaviours: A systematic review. Nutrition and Dietetics, 77(1), 4159. doi: 10.1111/1747-0080.12575

Paxton, S. J., Neumark-Sztainer, D., Hannan, P. J., \& Eisenberg, M. E. (2006). Body dissatisfaction prospectively predicts depressive mood and low selfesteem in adolescent girls and boys. Journal of Clinical Child and Adolescent Psychology, 35(4), 539-549. doi: 10.1207/s15374424jccp3504_5

Potterton, R., Richards, K., Allen, K., \& Schmidt, U. (2020). Eating disorders during emerging adulthood: A systematic scoping review. Frontiers in Psychology, 10, 3062. doi: 10.3389/fpsyg.2019.03062

Prichard, I., \& Tiggemann, M. (2012). Predictors of selfobjectification in new female fitness center members. Women in Sport and Physical Activity Journal, 21(1), 24-32. doi: 10.1123/wspaj.21.1.24

Prichard, I., \& Tiggemann, M. (2008). Relations among exercise type, self-objectification, and body image in the fitness centre environment: The role of reasons for exercise. Psychology of Sport and Exercise, 9(6), 855866. doi: 10.1016/j.psychsport.2007.10.005

Radwan, H., Hasan, H. A., Ismat, H., Hakim, H., Khalid, H., Al-Fityani, L., ... Ayman, A. (2019). Body mass index perception, body image dissatisfaction and their relations with weight-related behaviors among university students. International Journal of Environmental Research and Public Health, 16(9), 1541. doi: 10.3390/ijerph16091541

Richardson, M., Madzima, T., \& Nepocatych, S. (2019). Differences in body composition affect weight control practices and body image satisfaction in college students. Physical Activity and Health, 3(1), 1-10. doi: 10.5334/ paah. 28

Rockwood, N. J., \& Hayes, A. F. (2020). Mediation, moderation, and conditional process analysis: Regression-based approaches for clinical research. In A. G. Wright, \& M. N. Hallquist (Eds.), The Cambridge handbook of research methods in clinical psychology (pp. 396-414). Cambridge: Cambridge University Press. doi: 10.1017/9781316995808.037

Rohde, P., Stice, E., \& Marti, C. N. (2015). Development and predictive effects of eating disorder risk factors during adolescence: Implications for prevention efforts. International Journal of Eating Disorders, 48(2), 187198. doi: 10.1002/eat.22270

Sabiston, C. M., Pila, E., Vani, M., \& ThogersenNtoumani, C. (2019). Body image, physical activity, and sport:A scoping review. Psychology of Sport and Exercise, 42, 48-57. doi: 10.1016/j.psychsport.2018.12.010

Sa, J., Cho, B., Chaput, J., Chung, J., Choe, S., Gazmararian, J. A., ... Han, T. (2019). Sex and racial/ ethnic differences in the prevalence of overweight and obesity among US college students, 2011-2015. Journal 
of American College Health, 1-9. doi: 10.1080/07448481 .2019 .1679814

Sabiston, C. M., Pila, E., Vani, M., \& ThogersenNtoumani, C. (2019). Body image, physical activity, and sport:Ascoping review. Psychology of Sport and Exercise, 42, 48-57. doi: 10.1016/j.psychsport.2018.12.010

Schaefer, L. M., Burke, N. L., Thompson, J. K., Dedrick, R. F., Heinberg, L. J., Calogero, R. M., ... Swami, V. (2015). Development and validation of the sociocultural attitudes towards appearance questionnaire-4 (SATAQ-4). Psychological Assessment, 27(1), 54-67. doi: 10.1037/a0037917

Schwartz, S. J., \& Petrova, M. (2019). Prevention science in emerging adulthood: A field coming of age. Prevention Science, 20(3), 305-309. doi: 10.1007/s11121-019-0975-0

Seal, B. N., Bradford, A., \& Meston, C. M. (2009). The association between body esteem and sexual desire among college women. Archives of Sexual Behavior, 38(5), 866-872. doi: 10.1007/s10508-008-9467-1

Soulliard, Z. A., Kauffman, A. A., FittermanHarris, H. F., Perry, J. E., \& Ross, M. J. (2019). Examining positive body image, sport confidence, flow state, and subjective performance among student athletes and non-athletes. Body Image, 28, 93-100. doi: 10.1016/j. bodyim.2018.12.009

Sundgot-Borgen, J., Meyer, N. L., Lohman, T. G., Ackland, T. R., Maughan, R. J., Stewart, A. D., \& Müller, W. (2013). How to minimise the health risks to athletes who compete in weight-sensitive sports review and position statement on behalf of the ad hoc research working group on body composition, health and performance, under the auspices of the IOC medical commission. British Journal of Sports Medicine, 47(16), 1012-1022. doi: 10.1136/bjsports-2013-092966

Tomiyama, A. J., Carr, D., Granberg, E. M., Major, B., Robinson, E., Sutin, A. R., \& Brewis, A. (2018). How and why weight stigma drives the obesity 'epidemic' and harms health. BMC Medicine, 16(1), 123. doi: 10.1186/ s12916-018-1116-5

Tylka, T. L., \& Wood-Barcalow, N. L. (2015). What is and what is not positive body image? conceptual foundations and construct definition. Body Image, 14, 118-129. doi: 10.1016/j.bodyim.2015.04.001

Waasdorp, T. E., Mehari, K., \& Bradshaw, C. P. (2018). Obese and overweight youth: Risk for experiencing bullying victimization and internalizing symptoms. American Journal of Orthopsychiatry, 88(4), 483-491. doi: 10.1037/ort0000294

Wang, S. B., Haynos, A. F., Wall, M. M., Chen, C., Eisenberg, M. E., \& Neumark-Sztainer, D. (2019). Fifteen-year prevalence, trajectories, and predictors of body dissatisfaction from adolescence to middle adulthood. Clinical Psychological Science, 7(6), 14031415. doi: 10.1177/2167702619859331

Weinberger, N., Kersting, A., Riedel-Heller, S. G., \& Luck-Sikorski, C. (2016). Body dissatisfaction in individuals with obesity compared to normal-weight individuals: A systematic review and meta-analysis. Obesity Facts, 9(6), 424-441. doi: 10.1159/000454837

World Health Organization. (1997). Obesity: Preventing and managing the global epidemic: Report of a WHO consultation on obesity, no. WHO/NUT/NCD/98.1. Geneva, Switzerland: WHO.

World Health Organization. (2018). Global action plan on physical activity 2018-2030: More active people for a healthier world. Switzerland: WHO.

Yoon, C., Mason, S. M., Hooper, L., Eisenberg, M. E., \& Neumark-Sztainer, D. (2020). Disordered eating behaviors and 15-year trajectories in body mass index: Findings from project eating and activity in teens and young adults (EAT). Journal of Adolescent Health, 66(2), 181-188. doi: 10.1016/j.jadohealth.2019.08.012 